\title{
Análise dos casos notificados de sífilis gestacional e congênita entre os anos de 2014 e 2018 em Araguari - MG
}

DOI: $10.5935 / 2447-8539.201900018$

ISABELA OLIVEIRA ANDRADE; MARIANA LIMA SILVEIRA; PABLINE VANIN CLAUDINO; RAYSSA CARNEIRO FERREIRA; NATHÁLIA BORGES DE PAIVA; NATÁLIA DAVID VILELA; VANESSA LEMOS

e-mail: isab.oliveeira@gmail.com

\begin{abstract}
Resumo
Sífilis, ou LUES, é uma doença infectocontagiosa causada pela bactéria Treponema Pallidum (itálico). A principal via de transmissão é sexual, mas pode também ser transmitida verticalmente, da mãe para o feto, por transfusão de sangue ou por contato direto com sangue contaminado. Se não for tratada precocemente, pode comprometer vários órgãos como olhos, pele, ossos, coração, cérebro e sistema nervoso. Observou-se que nos últimos 10 anos, em especial a partir de 2010, ocorreu um progressivo incremento na incidência de Sífilis Congênita no Brasil. Tendo como base essa situação alarmante, o objetivo deste trabalho é avaliar o aumento da incidência de Sífilis Congênita por meio dos casos notificados. Trata-se de um estudo descritivo, epidemiológico, transversal e quantitativo em que a população é constituída por crianças nascidas em Araguari-MG diagnosticadas e notificadas com sífilis congênita com utilização também de dados secundários disponibilizados pelo DATASUS através do Sistema de Informação de Agravos de Notificação (SINAN) e do Sistema de Informações sobre Nascidos Vivos (SINASC). Esta pesquisa poderá contribuir para a evidenciação do porquê essa moléstia vem se agravando nos últimos anos e de acordo com essa informação investir em ações preventivas e de controle da infecção.
\end{abstract}

Palavras-chave: Incidência. Infecções por Treponema. Sífilis. Sorodiagnóstico da Sífilis.

\section{Abstract}

Syphilis, or LUES, is an infectious disease caused by a bacteria called Treponema pallidum. The main route of transmission is sexual, but it can also be transmitted vertically, from mother to fetus, by blood transfusion or through direct contact with contaminated blood. If not treated early, it can compromise various organs such as the eyes, skin, bones, heart, brain and nervous system. It was observed that in the last 10 years, especially from 2010, there has been a progressive increase in the incidence rate of congenital syphilis in Brazil. Based on this alarming situation, the aim of this paper is to evaluate the reason why of the increase in the incidence of Syphilis by means of the notified cases and the researching rapid test requests for pregnant women. This is a descriptive, epidemiological, cross-sectional and quantitative study in which the population consists of children born in Araguari in MG who were diagnosed and notified with congenital syphilis. A secondary data was provided by DATASUS through the Notification of Disease Information System (SINAN) and the Live Birth Information System (SINASC). This research may contribute to the evidence about the reason why this disease has been worsening in the recent years, so that according to this information investments in preventive actions and infection control can be made.

Keywords: $\quad$ Incidence. Treponema Infections. Syphilis. Syphilis Serodiagnosis. 


\section{INTRODUÇÃO}

A sífilis é uma doença bacteriana infectocontagiosa, provocada pelo agente etiológico Treponema pallidum. O principal meio de transmissão é por via sexual de forma vaginal, oral ou anal. Pode ocorrer também pelo contato com sangue infectado, no caso de transfusões ou acidentes com objetos perfurocortantes. Nas gestantes, quando a sífilis não é tratada, ou o tratamento é feito de modo incorreto, a infecção é transmitida verticalmente, de modo transplacentário, caracterizando a sífilis congênita (MINISTÉRIO DA SAÚDE. SECRETARIA DE VIGILÂNCIA EM SAÚDE, 2006).

O primeiro relato conhecido da doença data do século $\mathrm{XV}$, onde protagonizou uma das primeiras epidemias globais resultando em milhares de mortes pela Europa. A sífilis acompanhou as mudanças sociais com o passar dos anos e se tornou um problema de saúde pública no Brasil (BRASIL, 2006).

Com o advento da descoberta da penicilina em 1928, foi possivel controlar parcialmente a disseminação da doença, que contou com um reforço importante na década de 1980 que foram as campanhas para o uso de preservativos em decorrência do vírus da Aids. À medida que a moléstia foi sendo controlada, a Sífilis foi passou a não ser mais obrigatória a sua notificação nos sistemas de saúde para o Ministério de Saúde. Somente em 2010, sua notificação passou a ser obrigatória, devido ao grande aumento do número de casos no país e no mundo.

Apesar de ser facilmente curada com penicilina, devido à ausência de prevenção, falta de informação e tratamento inadequado, o país está encarando, novamente, um momento de epidemia.

Umas das maiores preocupações dessa comorbidade são as complicações derivadas da evolução da doença e da gravidade de consequências que acometem os recém-nascidos infectados. A taxa de transmissão transplacentária da Sífilis no período gravídico é uma das maiores entre todas as patologias de contágio vertical, representando aproximadamente um milhão de casos mundiais por ano, dentre esses 300.000 mortes fetais e neonatais, 200.00 podendo ocorrer em todos os trimestres da gestação. Além disso, a porcentagem de mortalidade pode ser até de $40 \%$ nos conceptos das mães que não receberam o tratamento, ocasionando abortos, natimortos e mortes no período neonatal (BRASIL, 2006).

A Sífilis Congênita (SC) é uma enfermidade que apresenta um impacto bastante relevante, fato é que, em 2010, a Organização Mundial de Saúde (OMS), juntamente com os estados membros da Organização Pan-Americana de Saúde (OPAS), propuseram e aprovaram uma estratégia que possuía como objetivo o Plano de Ação para Eliminação de Transmissão
Materno-infantil do HIV e SC no intuito de reduzir os casos de incidência de SC nos países das Américas (COOPER, 2016). Nessa situação, o Ministério da Saúde traçou uma meta de que até 2015 o número de SC seja inferior a 0.5 casos/1000 nascidos vivos (Boletim Epidemiológico, 2019). O Brasil não cumpriu o plano e apresentou um aumento significativo da incidência em SC em menores de 1 ano, apresentando em 2010 $(2,4 / 1000$ nascidos vivos) e 2015 (6,5/1000 nascidos vivos). Ao comparar a média nacional de 2015 (6,5/1000 nascidos vivos), a média regional nordeste $(7,1 / 1000$ nascidos vivos) e de outras regiões do mesmo ano, percebe-se a existência de uma variante regional e isso explica a relevância e a necessidade de traçar um perfil epidemiológico para possíveis ações futuras.

Nesse sentido, verifica-se a importância de se fazer o pré-natal adequado sendo este capaz de realizar detecção precoce da Sífilis materna e possibilitar o tratamento apropriado que previne a SC. Apesar de em 2005 o Ministério da Saúde (MS) criar medidas para planejar, avaliar, prevenir e controlar a sífilis em gestantes, nos últimos anos o cenário epidemiológico tem sido desfavorável com aumento de casos de sífilis e subnotificação de casos onde o país, ou seja, não iniciou o processo de certificação de eliminação da transmissão vertical. Diante disso, o MS tem elaborado cada vez mais Agendas Estratégicas para redução da SC devido a condição prioritária que é à prevenção da transmissão vertical da Sífilis.

\section{METODOLOGIA}

Trata-se de um estudo descritivo, epidemiológico, transversal e quantitativo no qual a população é constituída por crianças nascidas em hospitais em Araguari-MG que foram diagnosticadas por profissionais da área e foram notificadas com Sífilis Congênita. Definiu-se como caso de SC, toda criança, aborto ou natimorto de mãe com evidência clínica de Sífilis e/ou sorologia não Treponêmica reagente para Sífilis, com qualquer titulação, na ausência de teste confirmatório treponêmico realizado durante o prénatal ou no momento do parto ou curetagem, que não tenha sido tratada ou tenha recebido tratamento inadequado.

Os componentes foram descritos utilizando dados secundários disponibilizados pelo DATASUS através do Sistema de Informação de Agravos de Notificação (SINAN) e do Sistema de Informações sobre Nascidos Vivos (SINASC) exploradas com base nas abordagens metodológicas:

1. Descrição de tendências de indicadores associados a Sífilis no município de Araguari no recorte histórico formado pelos anos de 2014-2018 visando 
a descrição de tendências de indicadores associados à sífilis congênita:

a) Taxa de incidência dos casos de SC notificados no SINAN

b) Taxa de mortalidade - óbitos por SC obtidos do Sistema de Informações sobre Mortalidade-SIM

c) Taxa de internação hospitalar por Sífilis no Município de Araguari-MG

2. Descrição das características sociodemográficas das gestantes (faixa etária, raçalcor, escolaridades); variáveis em relação a gestação (realização do prénatal, evolução do caso, classificação final e tratamento do parceiro); dados do recém-nascido (idade do diagnóstico da SC, Sífilis materna e evolução do caso).

o processamento e a análise dos dados foram realizados por meio dos softwares do DATASUS e Excel com uso de estatística descritiva, esses dados foram apresentados em figuras e tabelas.

\section{DISCUSSÃO E RESULTADOS}

Os resultados deste estudo indicam uma oscilação no número de casos notificados de SC no período de 2014 a 2018. Referente a isso, houve um aumento constante e significativo de 2014 a 2017, dado que foi encontrado, também, em outras localidades brasileiras como observado no boletim epidemiológico da Sífilis emitido pelo MS em 2019. No entanto, ocorreu uma queda repentina no número de notificações no ano de 2018 (figura 1). Essa queda não seguiu a tendência de crescimento de outros estudos no período, como o realizado no município de Coromandel-MG, o qual manteve o crescimento (SILVA, 2018).

Figura 1. Número de casos notificados de SC em AraguariMG, 2014-2018.

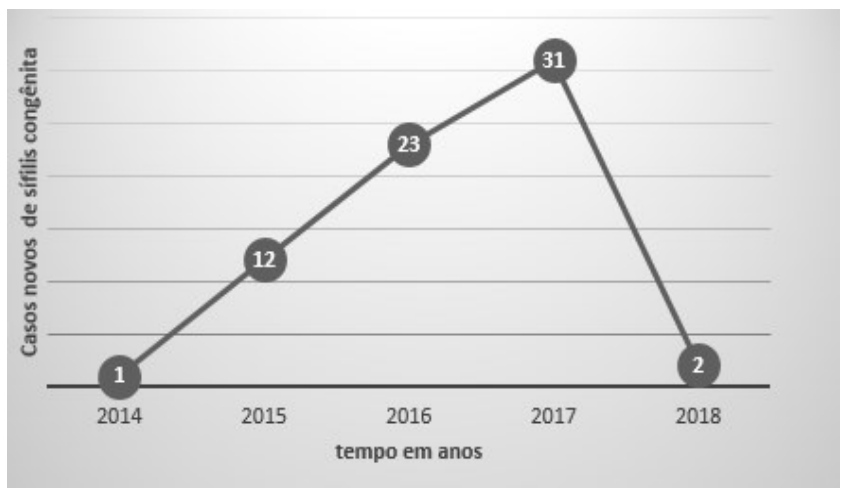

A situação observada reflete duas hipóteses. A primeira está relacionada a uma possível melhoria na qualidade da assistência e prevenção da Sífilis, devido a uma melhoria na gestão dos recursos financeiros e humanos destinados a esse fim, porém não temos acesso a dados objetivos e confiáveis que possam corroborar para essa hipótese.

A segunda justificativa pode estar relacionada às deficiências na notificação dos casos, com prováveis sub-registros e/ou subnotificações de casos. Um fato que corrobora para essa segunda justificativa são os dados nacionais contidos no boletim epidemiológico da Sífilis. Segundo Brasil (2019), em geral, nos últimos dez anos, diferentemente do verificado no município de Araguari-MG, houve um progressivo aumento na incidência de SC: em 2008 a taxa era de 2,0 casos/1.000 nascidos vivos e, em 2018, passou para 9,0 casos/1.000 nascidos vivos. Ademais, outros estudos têm demonstrado uma subnotificação de SC recorrente, ratificando nossa segunda justificativa para a queda das notificações no período (LAFETA et al., 2016; SOUSA et al., 2019; CLEMENTE et al., 2012).

Neste estudo, a grande parte dos SC $(97,1 \%)$ foi diagnosticada nos primeiros 6 dias de vida. No que refere à SC, a maioria dos RN não apresentam sintomatologia característica, dessa forma torna-se importante uma investigação na própria maternidade e pelos profissionais da atenção básica (BRASIL, 2013).

Quanto a realização do pré-natal, 89,9\% das mães de filhos com SC aderiram a esse tipo de assistência (tabela 1), o qual é preconizado pelo MS um número mínimo de seis consultas para ser considerado adequado e cujo objetivo é o desenvolvimento de uma gestação e um RN saudáveis, abordando aspectos psicossociais, atividades de prevenção e educação em saúde (BRASIL, 2013).

Tabela 1. Distribuição das características da assistência prénatal dos casos notificados de SC em Araguari-MG, 20142018.

\begin{tabular}{lcc}
\hline Características da assistência pré-natal & $\mathrm{Fi}$ & $\%$ \\
\hline Realizou o pré-natal & & \\
\hline Sim & 62 & 89,9 \\
Não & 5 & 7,25 \\
Ignorado & 2 & 2,9 \\
\hline Diagnóstico da sífilis durante o pré-natal & & \\
\hline Sim & 47 & 68,1 \\
Não & 19 & 27,5 \\
Ignorado & 3 & 4,35 \\
\hline Tratamento do parceiro & & \\
\hline Sim & 15 & 21,7 \\
Não & 44 & 63,8 \\
Ignorado & 10 & 14,5 \\
\hline
\end{tabular}


No que diz respeito aos casos de Sífilis gestacional, referentes às mães de RN com SC, diagnosticados durante o pré-natal, o número foi de $68,1 \%$, dado que vai ao encontro de um estudo realizado em Maringá/PR no qual a porcentagem foi de $78,23 \%$. Apesar disso, esse mesmo estudo do Paraná também mostrou que cerca de $64,07 \%$ dos parceiros não realizaram o tratamento por diversas razões, como a falta de contato da gestante com o parceiro, não comparecimento, entre outros motivos (PADOVANI; OLIVEIRA; PELLOSO, 2018). Esse número foi compatível com o presente estudo, em que $63,8 \%$ dos parceiros também não realizaram o tratamento.

No que tange o perfil escolaridade das gestantes diagnosticadas com SG em Araguari-MG, o estudo demonstrou que esse requisito é baixo corroborando estudos como os de Kilsztajn et al., (2003) em que se preconiza que as gestantes de baixa escolaridade têm maior risco para problemas relacionados a gravidez, parto e puerpério por isso necessitam de acompanhamento pré-natal mais específico para atenuar essa situação.

No tocante a raça/cor foi encontrada que a maioria das mulheres eram brancas (50,4\%), seguida por pardas (33\%) o que difere de Belo Horizonte cuja maior predominância foi em mulheres pardas (LIMA, 2013).

Outro fator importante é a faixa etária predominante das gestantes com Sífilis. Neste estudo foi observado predominância da idade de 20 a 39 anos correspondendo a 66,9\% dos casos, seguido de 30,9\% relacionado a idade de 15 a 19 anos. Resultados semelhantes foram encontrados em um estudo feito no estado do Piauí (Barbosa et al., 2013). Apesar de não ter sido o resultado predominante nos estudos, o número de adolescentes com Sífilis gestacional é relevante, fato também encontrado em Curitiba/PR, onde a situação é ainda mais prevalente (MOROSKOSKI et al., 2018).

\section{CONCLUSÕES}

Por meio deste estudo foi possível observar alguns pontos relevantes da assistência e prevenção da Sífilis: o tratamento inadequado dos parceiros, a investigação tardia da SG e a provável subnotificação dos casos de Sífilis Congênita (SC).

0 tratamento inadequado dos parceiros das gestantes com Sífilis mostrou-se uma realidade no Sistema Único de Saúde de Araguari, já que mais de 60\% dos parceiros não foram tratados, corroborando, logo, para o aumento do risco de transmissão vertical. Assim como, a investigação da Sífilis na gestação foi ineficaz, uma vez que quase $30 \%$ das gestante com Sífilis fizeram o diagnóstico após o período pré-natal. E, ainda, ocorreu uma provável subnotificação dos casos de SC, posto que tiveram um decréscimo surpreendente de 2017 para
2018, não se relacionando às curvas de diagnóstico de Sífilis, tanto no município de Araguari, quanto no Brasil, as quais mantiveram-se em crescimento.

Desse modo, para uma melhor assistência e prevenção da Sífilis em Araguari-MG, sugere-se necessário o empenho dos gestores em educação permanente das equipes de saúde. Essas equipes devem estar aptas a promover atividades de educação em saúde relacionadas a Sífilis. Ademais, sugere-se a implementação de ações a fim de intensificar a notificação, para reduzir o subregistro dos casos de Sífilis gestacional e congênita no município, uma vez que a notificação dos casos de SC constitui um instrumento efetivo e objetivo para implementação de novas políticas públicas em saúde.

Por fim, é necessário realçar a limitação quanto aos resultados deste estudo ao utilizar dados secundários com provável subnotificação e/ou possível viés de notificação. Logo, ressalta-se novamente a importância da qualidade dos registros referentes ao acompanhamento das gestantes nos prontuários eletrônicos.

\section{REFERÊNCIAS}

ALMEIDA, K. C. de; LINDOLFO, L. C.; ALCÂNTARA, K. C. de. Sífilis em gestantes atendidas em uma unidade de saúde pública de Anápolis, Goiás. Revista Brasileira Análises Clinicas;41(3):181-184, 2009.

BARBOSA, Débora Regina Marques, et al. Perfil epidemiológico dos casos de sífilis gestacional. Revista de enfermagem. UFPE online, 2017, 11.5: 1867-1874.

BRASIL. Ministério Da Saúde. Secretaria de Atenção à Saúde. Diretrizes para o Controle da Sífilis Congênita, 2006. Disponível em:<http://bvsms.saude.gov.br/bvs/publicacoes/manu al_sifilis_bolso.pdf >Acesso em: 05jun. 2018.

BRASIL. Ministério Da Saúde. Secretaria de Atenção à Saúde. Sífilis, Estratégias para diagnóstico no Brasil 2010. Disponivel

em:<http://bvsms.saude.gov.br/bvs/publicacoes/sifilis _estrategia_diagnostico_brasil.pdf >Acesso em: 05jun. 2018.

BRASIL. Ministério da Saúde. Secretaria de atenção à Saúde. Departamento de atenção básica . Atenção ao pré-natal de baixo risco. Brasília: Ministério da Saúde, 2013.

BRASIL. Ministério da Saúde (MS). Departamento de Doenças de Condições Crônicas e Infecções Sexualmente Transmissíveis (DCCI). Boletim Epidemiológico de Sífilis. Brasília: MS; 2019 [acessado 
2019 novembro 01]. Disponível em:

<http://www.aids.gov.br/pt-br/pub/2019/boletim-

epidemiologico-sifilis-2019>

CLEMENTE, T. S. et al. A importância do pré-natal como ferramenta na prevenção da sífilis congênita: revisão bibliográfica. Caderno de Graduação-Ciências Biológicas e da Saúde, Maceió, v. 1, n.1, p. 33-42, nov. 2012.

KILSZTAJN, S. et al. Assistência pré-natal, baixo peso e prematuridade no Estado de São Paulo, 2000. Revista de saúde Pública, n. 37: 303-310, 2003.

LAFETÁ, K. R. G. et al. Sífilis materna e congênita, subnotificação e difícil controle. Revista Brasileira de Epidemiologia; 2016, vol.19, n.1, pp.63-74.

LIMA, M. G. et al. Incidência e fatores de risco para sífilis congênita em Belo Horizonte, Minas Gerais, 20012008. Ciência \& Saúde Coletiva, 2013, 18: 499-506.

MAEDA, A. T. N. et al. Perfil clínico e epidemiológico das gestantes com Sífilis e Sífilis congênita no município de Cacoal, Rondônia, Brasil, 2007 a 2016. 2018. Revista Eletrônica FACIMEDIT, v7, n1,Jul/Ago 2018.

MOROSKOSKI, M. et al. Perfil de gestantes adolescentes diagnosticadas com sífilis em CuritibaPR. Revista de Saúde Pública do Paraná, 2018, 1.1: 47-58.

PADOVANI, C.; OLIVEIRA, R. R. de; PELLOSO, S. M. Sífilis na gestação: associação das características maternas e perinatais em região do sul do Brasil. Rev. Latino-Am Enfermagem, vol.26 Ribeirão Preto, 2018.

SILVA, N. G. da. Avaliação de prevalência de Sífilis no município de Coromandel, MG, Brasil entre os anos de 2012 a 2018. 11f. 2018. TCC. Fundação Carmelitana Mário Palmério, 2018.

SOUSA, O. C. et al. Sífilis congênita: o reflexo da assistência pré-natal na Bahia. Brazilianjournalof Health Review, Curitiba, v. 2, n. 2, p. 6, 1356-1376, mar./apr. 2019. 